$A L, 2,2002-14$

4.2

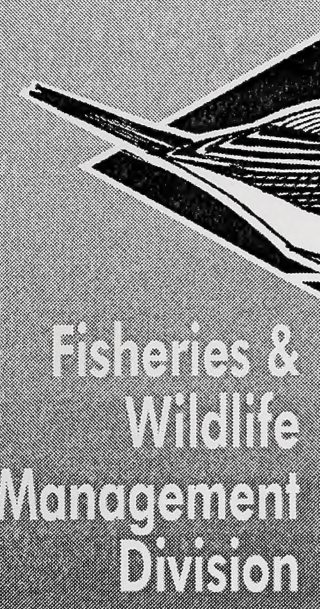

RESOURCESTATUS AND ASSESSMENT BRANOH

\title{
Carnivores and Corridors in the Crowsnest Pass
}

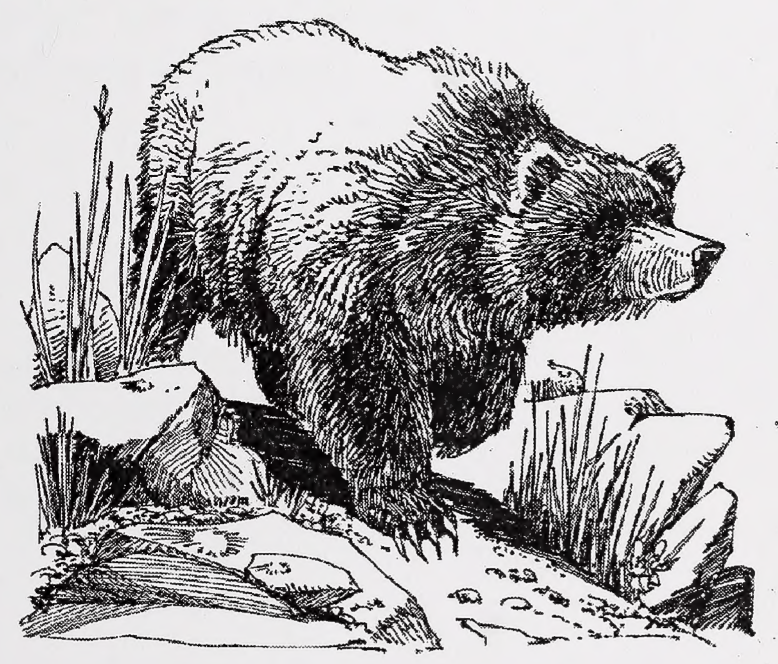

Alberta Species at Risk Interim Report 
Digitized by the Internet Archive in 2016 


\title{
Carnivores and Corridors in the Crowsnest Pass
}

\author{
Prepared by: \\ Cheryl-Lesley Chetkiewicz \\ Department of Biological Sciences \\ University of Alberta
}

\author{
Prepared for: \\ Alberta Environmental Protection \\ Natural Resources Service \\ Fisheries and Wildlife Management Division
}

Alberta Species at Risk Interim Report

April 2001 
For copies of this report, contact:

Information Center- Publications

Alberta Environment

Natural Resources Service

Main Floor, Great West Life Building 9920- 108 Street

Edmonton, Alberta, Canada T5K 2M4

Telephone: (780) 422-2079

OR

Information Service

Alberta Environment

\#100, 3115- 12 Street NE

Calgary, Alberta, Canada T2E 7J2

Telephone: (403) 297- 3362

\section{OR}

Visit our web site at:

http://www.gov.ab.ca/env/fw/status/reports/index.html

This publication can be cited as:

Chetkiewicz, Cherly-Lesley. 2001. Crowsnest linkage project progress report \# 1: Carnivores and Corridors in the Crowsnest Pass. Alberta Sustainable Resource Development, Fisheries and Wildlife Management Division, Edmonton Alberta. Interim Report. 
Acknowledgements.

Executive Summary

Carnivore Biology and Conservation...........................................................

Responses of Grizzly Bears and Cougars to Human Activities................................. 8

Wildlife Corridors: Bears and Cougars................................................. 10

Assessing the Location and Utility of Wildlife Corridors for Grizzly Bears and Cougars in the Crowsnest Pass: A Proposal............................................................... 12

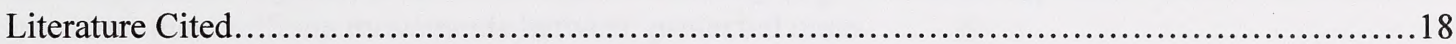


I would like to thank Richard Quinlan, Jim Clark and Kirk Olchowy with Alberta Environment for their time and input during our meetings in Blairmore.

This document was developed under contract to the Alberta Environment Agreement No. PR015033. The terms of reference for this report issued under this contract are as follows:

1. Conduct a review of selected scientific literature on carnivore biology and conservation, the responses of grizzly bears and cougars to human activities, and relevant corridor and fragmentation studies and present in a report.

2. Develop project design for a 3 year study modelling and measuring actual carnivore use in Crowsnest Pass, to determine preferred habitats and movement corridors, and to verify areas for habitat securement and present in a report. 
Habitat loss, fragmentation and the isolation of habitat fragments due to human activities are major threats to the conservation of biodiversity. Understanding the effects of increasing human activities and habitat fragmentation on large, mobile organisms such as carnivores remains a crucial challenge for wildlife managers who are required to balance human use and the conservation and management of these species. Grizzly bears and cougars have a high conservation and management interest in Alberta and Canada. They have large home ranges, exist at relatively low population densities, and require adequate prey populations. They are susceptible to local extinction in existing protected areas and typically subjected to high mortality rates outside and on the edges of these areas due to conflicts with humans. Managing carnivores in human dominated landscapes is complicated because little is known about the ecological processes and patterns at the spatial and temporal scales that characterize their life history requirements. The links between populations, behavior, and landscape structure are not well understood nor how these processes may change with increased human use and development. As such, carnivore conservation strategies have focused on the development of regional reserve networks consisting of protected areas, buffer zones, and wildlife corridors that facilitate movements between protected areas.

Little is known about how to design corridors in landscapes that include carnivores or how to assess the utility and effectiveness of designated corridors for enhancing movement of individual carnivores and maintaining local and regional populations of carnivores. A few observational studies have illustrated the utility of corridors in urban-wildland landscapes. Telemetry studies have been used to help define where corridors are located. Models have been used to illustrate the importance of maintaining corridors to ensure local population survival. Statistically robust experiments to test the effects of corridors at a scale considered to be appropriate for large carnivores is deemed to be too expensive, labor-intensive and not practical under most circumstances. Managers must often define and secure wildlife corridor designations without sitespecific empirical data on resource selection and movement patterns of target species. As such, it is difficult to justify habitat enhancement or restoration efforts, prioritize habitat securement efforts, or develop appropriate mitigation responses. Similarly, it is difficult to understand how movement and resource selection patterns may change with changes in the landscape structure. Quantitative understanding and prediction based on the consequences of movement over space and time, is almost impossible without models. We do not have the ability to directly ask why a carnivore makes certain behavioral decisions nor can we perform experimental work at large spatial or temporal scales. Therefore, models are critical to our understanding of ecological processes and provide a platform or framework on which we can develop and test our understanding.

An approach to define potential corridors for grizzly bears and cougars in the Crowsnest Pass is presented. This approach uses a suite of new tools in wildlife management including remote sensing, Global Positioning System (GPS) telemetry, geographical information systems (GIS) technologies, and spatially explicit habitat models, based on Resource Selection Functions (RSF), and movement models to assess the links between landscape structure and resource selection and movement patterns of grizzly bears and cougars in the Crowsnest Pass. This approach will allow managers to prioritise and co-ordinate habitat management efforts for carnivores and their ungulate prey. This approach can provide managers with a way of assessing mitigation options for ensuring movement through fragmented landscapes and thereby capitalize on opportunities to bring together conservation organizations, industry, and landowners and meld game management and preservation interests in Alberta. Regionally, the results will support and link with ongoing carnivore planning and conservation efforts in the Rocky Mountains such as the Yellowstone to Yukon (Y2Y) Project. 


\section{Carnivore Biology and Conservation}

Habitat loss, fragmentation and the isolation of habitat fragments due to human activities are major threats to the conservation of biodiversity (Wilcox and Murphy 1985). Drawing from the theory of island biogeography (MacArthur and Wilson 1967), metapopulation models (Hanski and Gilpin 1991), proposed as a framework for the demography and spatial distribution of populations in fragmented or heterogeneous landscapes, assume that several patch populations are connected by animal movements between patches to recolonize local extinctions and prevent regional extinction (Crone et al. 2001). Landscape ecology incorporates the concepts of spatial heterogeneity, edges, patches and scale. Landscapes that incorporate the patterns and processes of ecological interactions between communities or ecosystems are considered to be the appropriate scale for management and conservation (Turner 1989). Landscape ecology and the quantitative techniques and models developing in association with this evolving discipline are essential tools for describing and ameliorating the effects of habitat destruction and fragmentation (Turner and Gardner 1991).

Large carnivores such as grizzly bears and cougars have been proposed as surrogate species for biodiversity conservation strategies (Lambeck 1997). The effects of large carnivores on prey, other carnivores, and vegetation are considered important in structuring and maintaining biodiversity within terrestrial communities (Terborgh et al. 1999). They are considered to be umbrella species because they have large home ranges that may encompass populations of species with smaller home ranges (Noss et al. 1996, but see Andelman and Fagan 2000). Mammalian carnivores however are sensitive to changes in landscape structure due to their low population densities, low fecundity, and their limited dispersal ability across open or developed habitats and consequently they are susceptible to habitat fragmentation, particularly due to human activities (Weaver et al. 1996). Due to their life history traits, large carnivores rarely remain within the boundaries of protected areas that are often too small to conserve viable populations or contain enough suitable habitat to support these animals throughout the year (Noss et al. 1996). Large carnivores that move outside or along the edges of protected areas experience high mortality rates due to conflicts with humans (Woodroffe and Ginsberg 1998). Increasing anthropogenic pressures from industry, recreation, and suburban and highway expansion outside of protected areas may restrict individual movements and population viability and exacerbate the conflicts between humans and wildlife. Carnivore conservation strategies to offset these effects have focused on the development of regional reserve networks consisting of protected areas, buffer zones, and wildlife corridors that facilitate movements between protected areas (Soulé and Terborgh 1999).

\section{Movement:}

Movement of individuals is fundamental to a host of ecological processes such as population spread and redistribution (Turchin 1998), metapopulation dynamics (Hanski 1998), local species richness (Fahrig and Merriam 1994), local and regional population dynamics (Kareiva 1990, Dunning et al. 1992), inbreeding depression and opportunities for local adaptation (Hastings and Harrison 1994). Movement paths reflect an individual's behavioral response to the environment at a variety of temporal and spatial scales and are therefore critical to assessing and understanding the impact of changes in landscape structure. Movement among patches is a function of the organism's use, ability to move, and movement rates among patches as well as the landscape structure itself. This interaction has been defined as connectivity which is the degree to which a landscape facilitates or impedes movement of organisms among resource patches resulting in recolonization and/or local extinctions of populations (Tischendorf and Fahrig 2000). Quantitative methods for the study of animal movement have been established (Turchin 1998). The majority of the empirical work on movement has focused on invertebrates (Turchin 1998). 
Kozakiewicz and Szacki (1995) reviewed the information on small-mammal movements in heterogeneous landscapes. They suggested that most of the literature was devoted to documenting dispersal and population consequences, but individual movements were rarely documented making it difficult to understand the patterns at the population level. Data on movements within home ranges were inconsistent between studies and the results depended strongly on the methodology used to either collect the data or analyze the information. They noted that the scale at which the studies were conducted $(<1 \mathrm{ha})$ had biased the understanding of movement and population level processes and patterns in that there was considerable mobility of small mammals and the greater the heterogeneity, the greater the mobility. They felt different species of small mammals had different strategies for dealing with landscape heterogeneity. Stern (1998) reviewed the effects of landscape structure, scale, and movement in field experiments with large mobile organisms. He suggested that the study of mobility in large organisms was really the study of individuals and the use of models were necessary to address dynamics at more realistic spatial and temporal scales. Even with conventional telemetry, the quantitative measurement of movement is rarely addressed (Turchin 1998). With the advent of GPS collars, the opportunity to obtain frequent and accurate relocations of large mammals and the reconstruction of movement paths at a variety of spatial and temporal scales is possible. Although we can quantify different types of movement (daily and seasonal movements as well as long-distance movements), the roles of biotic and abiotic factors affecting the movement of individuals, whether large or small, are not well understood (Turchin 1998, Gilliam and Fraser 2001). Landscape structure modeled within a GIS provides a realistic approach to assessing animal movement and the potential effects of management or conservation actions on animal movement and population dynamics can be examined (Folse et al. 1989, Turner et al. 1993, Liu et al. 1995, Rushton et al. 1997, Stern 1998, Wei and Jeske 2000).

\section{Wildlife Corridors}

Corridors are thought to enhance long-term survival of populations by facilitating movement of individuals in order to reduce the vulnerability of insular populations to stochastic extinction and provide a means for recolonization by permitting dispersal and allowing animals to escape unfavorable conditions within patches (Brown and Kodric-Brown 1977, Simberloff and Cox 1987, Noss 1992, Fahrig and Merriam 1994, Rosenberg et al. 1997). Corridors are not consistently defined, but typically mean linear, continuous strips of habitat that connect two otherwise noncontiguous habitat patches (Saunders and Hobbs 1991, Hobbs 1992, Jalkotzy et al. 1997). Corridors can be natural or remnant features such as hedges and riparian strips (Bennett et al. 1994) or disturbed features resulting from human activities such as linear developments like roads, logging buffers, and powerline strips (Schmiegelow et al. 1997, Jalkotzy et al. 1997). They can function in a number of ways: habitat, conduits, filters or barriers, sources, and sinks (Merriam 1991, Jalkotzy et al. 1997). Wildlife corridors are considered to be most useful if they can facilitate movement and as such they are usually defined as transitional habitats (Soulé 1991). The more similar the corridors are to the patches that they connect, the more effective they will be in functioning as conduits for daily, seasonal and long-distance movements such as dispersal and migration (Lidicker, Jr., and Koenig 1996).

Observational, experimental, and modeling approaches have been applied to address the value and utility of corridors for different species, particularly small mammals, birds, and insects (Rosenberg et al. 1997, Beier and Noss 1998, Haddad et al. 2000). However, statistically robust experiments to test the effects of corridors at the scale appropriate for large mobile mammals like carnivores are considered too expensive, labor-intensive and not practical under many circumstances (Nicholls and Margules 1991, Inglis and Underwood 1992). Though the value and utility of corridors remains scientifically debatable (Simberloff and Cox 1987, Noss 1987, Hobbs 1992, Simberloff et al. 1992), 
they continue to be promoted in the conservation literature as a practical approach to management (Little 1990, Hudson 1991, Smith and Hellmund 1993) and conservation (Noss 1983, Saunders and Hobbs 1991).

One source of semantic confusion is the concept of connectivity. Tischendorf and Fahrig (2000) suggested that corridors may be a component of landscape connectivity, but the degree to which they contribute to connectivity depends on the nature of the corridors, the nature of the matrix and the response of the organism to both (Rosenburg et al. 1997, Beier and Noss 1998). Connectivity is both species- and landscape-specific and must be described from the species' point of view (Wiens and Milne 1989). Consequently, it is important to define the species' habitat or resource needs; determine the scale at which the species' is responding to the landscape at both the fine-scale (grain) and large-scale (extent) (Wiens 1991); and, assess how the species responds to the different elements and changes in the landscape at different scales.

Designing corridors is complicated because of the difficulty in addressing species and scale specific details, conflicting land use policies on the landscape, and the cumulative effects of different land uses on individuals and populations (Merriam 1995, Beier and Loe 1992, Paquet et al. 1994, BCEAG 1999). The quantity and quality of the corridor in facilitating movement for target species can be generalized to include the quality of the habitat that the corridor connects, the location of the corridor, its width, length, and shape, the availability of cover, the ease of travel, the level and type of human use within and adjacent to the travel route, and the extent to which users of the corridor are habituated to human developments and activity (Heuer 1995). However, managers must often define and secure wildlife corridor designations without site-specific empirical data on resource selection and movement patterns of target species. Having these data is important since different species react differently to the availability and quality of corridors and the human induced changes, activities, and developments on the landscape (Jalktozy et al. 1997). 


\section{Grizzly Bears and Human Activities}

Grizzly bears are the most omnivorous large carnivores. They require habitats with high quality seasonal food resources that allow them accumulate enough fat reserves for hibernation (Weaver et al. 1996). The persistence of grizzly bear populations in the southern Canadian Rocky Mountains and the contiguous United States is linked to human-caused mortalities and human impacts on grizzly bear habitats (Bunnell and Tait 1981, Servheen 1990, Stringham 1990, McLellan 1994). In general, grizzly bears are sensitive to human disturbance and activities as well as human developments, particularly roads (McLellan 1994, Weaver et al. 1996, Jalkotzy et al. 1997). Jalkotzy et al. (1997) provided an excellent review of the effects of human activities, specifically linear developments such as roads, railroads, and highways on grizzly bears. Mattson et al. (1996) also highlighted the effects of human activities, particularly roads, on grizzly bear behavior and habitat use.

Grizzly bears are classified as vulnerable at the Federal level and are considered a species which may be at risk in Alberta (Blue List) (Benn et al. 1998). Intensive grizzly bear studies have been conducted throughout the province including: South Wapiti, Swan Hills, Berland Wildhay, Jasper National Park (JNP), BNP, Kananaskis Country, and Waterton Lakes National Park (summarized in Nagy and Gunson1990). More recently, grizzly bears were studied in the Bow River Watershed (Gibeau 2000), the Yellowhead Ecosystem (Stenhouse and Munro 2000), and southwestern Alberta (Mowat and Strobeck 2000). In Alberta, grizzly bears are forced into higher elevations as industrial and recreational development, roads, and suburban expansion now characterize the more productive grizzly bear habitat at low elevations. In addition, the mountain national parks in Alberta do not provide adequate quantities of prime grizzly habitat. For example, only $53 \%$ of BNP is considered suitable grizzly bear habitat, which is further reduced by townsites, roads, recreational developments, and human use within the Park (Green et al. 1996).

In Alberta, the relationship between grizzly bears and agricultural, industrial and recreational development has been documented (McCrory and Herrero 1982, Horejsi 1986 cited in Apps 1993, Herrero et al. 1986, Nagy and Gunson 1990). Purves et al. (1992) reported that human-use levels in Banff, Yoho, and Kootenay National Parks exceeded the tolerance of non-habituated bears resulting in habitat avoidance. Gibeau (2000) and Gibeau and Heuer (1996) documented the effects of highways on grizzly bear movements and found that the Trans-Canada Highway (TCH) was an effective barrier for adult females as no radio-collared females crossed the TCH and a filtered barrier for adult males. Clevenger and Waltho (2000) analyzed carnivore activity at eleven wildlife underpasses in BNP and found carnivore use in general was positively correlated with distance to townsites and negatively correlated with human use around or in underpasses. Grizzly bears did use two of the underpasses. Grizzly bears also suffer direct morality due to human activities such as hunting and problem responses and in collisions on highways and railroads (Gunson 1995).

A cumulative effects model (CEM) was developed for grizzly bears in BNP and JNP in Alberta, and Yoho and Kootenay National Parks in British Columbia (Green et al. 1996). This model created an index of habitat effectiveness for each bear management unit within the Parks given habitat quality and human disturbance. It was based on grizzly bear food habits and habitat use studies within the Parks and human disturbance values adopted from the Yellowstone ecosystem. Herrero and Herrero (1996) used this model to address the effects of a coal pit mine in west central Alberta. The CEM approach was extended to model bear dispersal paths in BNP and surrounding area with a Linkage Zone Prediction (LZP) model. The LZP predicts the relative probability of grizzly bear movements given human development features (towns), linear disturbance elements (roads, railroads), visual 
cover, and riparian habitat. It was not based on any empirical grizzly bear movement data for the area since none existed at the time (Green et al. 1996). An LZP approach was also applied to Highway 3 in both southeastern BC and southwestern AB (Apps 1997).

\section{Cougars and Human Activities}

In general, cougars are tied to cervid populations, their main prey, therefore management, protection and enhancement of habitats for cougar prey populations are considered important to sustaining cougar populations (Carroll et al. 2000). Cougar habitat can be characterized by the presence of sufficient prey that is deer-sized or larger and terrain that facilitates predation on that prey (e.g., snow and cover).

In Alberta, cougars are a management and conservation concern (Yellow B List). Only one intensive cougar study has been conducted in Alberta. From 1981-1989, the Sheep River Cougar Project investigated cougar ecology in the foothills of the Rocky Mountains in southwestern Alberta (Ross and Jalkotzy 1992) providing the scientific basis for the Alberta Cougar Management Plan (Alberta Fish and Wildlife 1992). Jalkotzy and Ross (1991) also summarized the available data on cougars within Alberta's National Parks.

Limited scientific data is available on cougar responses to human activities (Weaver et al. 1996, Jalkotzy et al. 1997). In Alberta, Jalkotzy et al. (1999) found male and female cougars avoided areas of high human use (250-500 users/month) throughout the year in the Sheep River study area, but did not avoid low-use trails and roads in the winter. Cougars suffer direct mortality through hunting especially when winter snow-tracking conditions facilitate locating and hunting cougars. For example, the Albertan cougar harvest seemed to be linked to the degree of motorized access (Jalkotzy et al. 1997). Existing highway underpasses in Canmore and BNP appear to function for cougars (Clevenger 2000, Clevenger and Waltho 2000, Gibeau and Heuer 1996). Callaghan and Jevons (2001) reported that cougars adjusted well to human activity in their corridor study area and suggested that cougars may benefit from human activity as domestic dogs were documented as being prey items. 


\section{Grizzly Bears}

Mattson et al. (1996) suggested that there was no evidence that North American grizzly bears populations were characteristically fragmented or exhibited a metapopulation structure prior to the arrival of Europeans. Mortality of grizzly bears associated with human access has been described as a source-sink model where areas near human facilities are considered sinks and parks are considered sources (Doak 1995). Nagy and Gunson (1990) postulated that this was the structure of grizzly bear populations in southern Alberta. Increasing the exchange between small, otherwise vulnerable populations is theoretically good for grizzly bears (Harrison 1991). Noss (1992) suggested that functional linkage corridors for grizzly bears should be about twice the width of the mean life range of an adult male. Mattson et al. (1996) felt that the functionality of corridors could only be considered when populations were within a range of lifetime movements. Populations isolated from each other beyond these distances will not benefit from corridors as currently defined. There is limited data on dispersal for grizzly bears and long distance movements of male grizzly bears (Blanchard and Knight 1991, Boone and Hunter 1996, Craighead and Vyse 1996). Ruckelshaus et al. (1997) showed that errors in estimating these distances had important consequences for model results.

Picton (1986) suggested that a functional linkage ("corridor") was possible between the Yellowstone and Glacier National Park area. Bader (2000) conducted a spatial analysis of grizzly bear populations in the US Rockies using a minimum corridor width for males and females based on broad habitat categories (mesic (South Fork Flathead, Selkirk and Cabinet-Yaak) and xeric (Yellowstone and Rocky Mountain Front areas)). His analysis of potential linkages combined with dispersal distances showed that secure areas were spatially distributed within known dispersal distances for male and female grizzly bears.

In Alberta, most of the research on corridor use is based in BNP or in the Canmore corridors takes place during the winter months using snowtracking techniques (Heuer 1995, Stevens et al. 1996, Heuer et al. 1998, Duke 2000, Callaghan and Jevons 2001). Consequently, there is little data on the summer use of these corridors by grizzly bears.

\section{Black Bears}

Several studies suggest that black bears use corridors both for seasonal movements and dispersal. Kellyhouse (1977) and Weaver et al. (1990 cited in Harris et al. 1996) found that bears used riparian strips to move within fragmented strips. Manville (1983) reported that linear developments were serving as travel corridors for black bears in Michigan. Beecham (1983) showed that migration corridors within this study area were important for maintaining black bear populations in Idaho. Mollohan and Lecount (1989 cited in Harris et al. 1996) showed that canyons with suitable cover were used by black bears during seasonal foraging trips.

\section{Cougars}

The use of corridors and remnant habitat patches by cougars has been intensively studied in Florida (Maehr and Cox 1995, Maehr 1990). Landscape structure and cougar radio data locations were analyzed to identify what lands and habitat variables were important for cougar conservation. The authors did not designate wildlife corridors for cougars nor did their analyses reveal any minimum functional corridor dimensions. Cougars used bands of remnant forest as narrow as $100 \mathrm{~m}$ as they moved through the agricultural and urban landscape (Maehr 1990). 
In southern California, Beier $(1993,1995,1996)$ documented the use of three remnant corridors and several habitat patches by resident and dispersing cougars that were semi-isolated by urbanization. Five of the nine dispersers found and used these corridors. He documented their movements with respect to roads and found that topography and vegetation were critical in determining the quality of the corridors for cougars. The locations of these corridors were critical with respect to road crossings. Beier $(1993,1996)$ simulated the resulting population dynamics for this population. He showed that for best estimates of parameters, the population faced a 3\% risk of extinction in the next 100 years with current amount of habitat. Reducing the habitat by $40 \%$ (a likely scenario) increased the probability of extinction to $33 \%$. The results suggested that fragmentation would be detrimental to local populations and remnant corridors had to be maintained if these populations were to persist. In this study, the results of the field data and a quantitative model were used to restore and protect these corridors.

Ruth et al. (1998) monitored the movements of translocated cougars in New Mexico. These animals often moved along the urban-wildland interface in remnant corridors. Ruth et al. (1998) recorded the movement behaviors in response to obstacles and barriers and used these data to suggest that barriers for translocated cougars had similar ramifications to naturally dispersing cougars in the region.

Sweanor et al. (2000) examined cougar dispersal, emigration, and immigration to assess the effects of dispersal on the local and surrounding metapopulations. They examined movements across potential barriers such as highways and the use of remnant habitat corridors along the mountain ranges. They did not identify distinct habitat corridors but inferred that their study areas functioned as "corridors" depending on the dispersal success.

In Alberta, Heuer (1995), Stevens et al. (1996), Heuer et al. (1998) and Duke (2000) documented cougar use in four areas subject to medium and high levels of human use where movements were restricted because of the TCH. Snow tracking within these four corridors indicated that cougars preferred to use the Norquay-Cascade remnant corridor that was $200-800 \mathrm{~m}$ wide and $8 \mathrm{~km}$ long (Stevens et al. 1996). Callaghan and Jevons (2001) documented winter cougar use in a remnant corridor in the Canmore region of the Bow Valley. 
Assessing the Location and Utility of Wildlife Corridors for Grizzly Bears and Cougars in Crowsnest Pass: A Proposal ${ }^{1}$

\section{Goal}

The goal of this research project is to define the location and utility of wildlife corridors for two large carnivore species within the south Bow Crow Forest in the Canadian Rocky Mountains.

\section{Objectives}

1) Collect data on resource selection and movement patterns of grizzly bears and cougars in Crowsnest Pass. I will capture and apply a Global Positioning System (GPS) collar to five cougars and five grizzly bears within the study area. I will develop a basemap consisting of data layers for habitat variables such as vegetation and prey density, topographic variables such as elevation and human disturbance variables such as roads, road density, and human population density.

2) Compile existing distribution and survey data for elk and bighorn sheep in the Crowsnest Pass. In collaboration with the Alberta Fish and Wildlife Service (F\&W), these data will be compiled to assess population parameters, habitat selection, and movement patterns of bighorn sheep and elk as well as any information on habitat values for their winter and summer ranges. These data will be used to develop an index of potential ungulate prey density for the study area.

3) Develop spatially explicit habitat and movement models that map the probability of occurrence of grizzly bears and cougars given current landscape condition. I will compare the location data of each bear and cougar with the available habitat by develop an RSF model for each animal and for each species. GPS telemetry data will be analyzed to quantify movement parameters such as direction, duration, distance, and probability of individual movements at different scales (Turchin 1998). I will use the same habitat variables studied for RSFs, to predict where the highest probability of grizzly bear and cougar movements will occur given current landscape structure.

4) Compare the model predictions with designated or planned "paper" corridors and highway mitigation structures. I will assume that the predictions of the RSF models and the movement models are the most suitable areas for grizzly bears and cougars given their resource selection and movement patterns. Using a GIS, I will compare the model predictions with planned corridors and highway expansion mitigation structures.

\section{Methods}

\section{Capture and Telemetry:}

Five grizzly bears and five cougars will be captured annually using snares and hounds, respectively in each study area. The Canadian Council on Animal Care will review procedures for capture operations. Standard measurements will be collected and samples taken for genetic and health analyses (blood, hair, feces). Grizzly bears will be captured in spring and summer. Cougars will be captured in the fall and winter given adequate snow conditions for tracking. To obtain the most precise data on temporal and spatial habitat use, captured grizzly bears and cougars will be fitted with a GPS collar. Grizzly bear collars will be programmed to obtain 24 positions per day at 1-hour intervals for approximately 395 days. Because the cougar collars are smaller, collars will be programmed to record a position 12 times per day at 2-hour intervals for approximately 166 days. Collars will be downloaded from the ground or aircraft approximately every 2 months. A drop off mechanism on the grizzly bear GPS collar will be activated in the following spring following den emergence. Collars will be retrieved and refurbished. Current limitations in collar design restrict the use of a drop off mechanism on the cougar collars therefore necessitating recapturing the cougar

\footnotetext{
${ }^{1}$ The proposed research presented here is a draft and subject to review and revision by my Ph.D. committee.
} 
to replace the collar after 5 months and at the end of data collection period. Collaring will continue in 2002-2004 to obtain a representative sample (males, females, subadults, adults) of individual bears and cougars that are using the study area at some point during the year.

\section{Data Layers:}

\section{Animals:}

Attributes for each collared grizzly bear and cougar such as sex, age, and physical condition will be recorded at the time of capture. Data on the presence of cubs and kittens will be collected if possible. Location data from the collared bears and cougars will be plotted and home ranges will be determined (Stenhouse and Munro 2000). Existing distribution and survey data for ungulate prey species such as elk and bighorn sheep in the Crowsnest Pass will be compiled from F\&W, Parks Canada, and BC Ministry of the Environment, Lands, and Parks sources where available.

\section{Vegetation:}

A satellite image of the study area will be obtained to measure greenness, a measure highly correlated with deciduous green vegetation that has been used as a surrogate for grizzly bear habitat quality (Mace et al. 1999, Gibeau 2000) and ungulate prey density for cougars (Carroll et al. 2000). Fire data including location, size, age, and year will be obtained for the study areas. Existing habitat enhancement or management projects will also be incorporated.

\section{Climate and Topography:}

Elevation, slope and aspect in the study areas will be classified from a Digital Elevation Model (DEM). Only elevations below $2,400 \mathrm{~m}$ will be considered in the analysis for grizzly bears since Gibeau (2000) showed that this was the upper limit for grizzly bear foraging in the Bow Valley. Site severity index (SSI) will be calculated. SSI integrates aspect and slope and represents the amount of direct solar radiation and heating of site in relation to a flat surface (Beers et al. 1966). Snow depth and topographic complexity, considered important habitat variables for cougars, will be included (Jalkotzy et al. 1999). Daily and seasonal weather data such as maximum and minimum temperatures and precipitation in the study areas will be obtained from Environment Canada records.

\section{Human Disturbance:}

Linear developments such as roads, seismic lines, railroads, and recreational trails will be plotted. All known "points" of human activity will be digitized as disturbance sources. Land use data such as ownership (private or Crown land), zoned or designated land parcels for agriculture, recreation, industry, etc. and Wildlife Management Units will be obtained for the study areas.

Data on roads and trails in the study areas will be obtained, digitized where necessary, and categorized according to permanence, speed restrictions, or designated regulations (Gibeau 2000). In the Crowsnest Pass, there are currently no road or wildlife crossing monitoring protocols on Highway 3. In consultation with the Department of Transportation and F\&W, the number of vehicles will be tallied using traffic counters.

During the winter, snow tracking along systematic transects will be established along Highway 3 to determine presence/absence, direction of travel, and highway crossing points during the winter following similar monitoring protocols for BNP and Canmore. In addition, remote cameras will be placed at key sites where terrain and habitat provide cover and security for possible movement routes. Data from GPS collared cougars and grizzly bears as well as data from other research in the study area will be compiled to show crossing points on roads and railroads. 
Data on human population size within the study areas and surrounding region will be obtained from census data for towns and counties. Seasonal human use on trails is not known in Crowsnest Pass. However, a workshop is planned in Canmore to establish standardized protocols for monitoring human use on trails. Using these protocols, comparable data for Crowsnest Pass will be collected using similar direct and indirect methods. Following Merrill et al. (1999) these indices, in combination with total number of people living within the study area and vicinity, will be used to develop a function of the potential number of people $/ \mathrm{km}^{2}$ using trails on a monthly, seasonal, and annual basis. Statistics on snowmobile activity and human use during the winter will be compiled from existing sources through clubs or municipal sources.

Grizzly bear and cougar mortality due to humans e.g., roads, railroads, hunting, or problem control actions (e.g., translocation or killing) for the study area will be compiled from existing data sources with Parks Canada, Alberta Fish and Wildlife, Alberta Infrastructure, and other projects such as East Slopes Grizzly Bear Project (ESGBP).

\section{Resource Selection Function Models: Development and Analyses}

Prior to the development of RSFs, there were no predictive models linking habitats and populations that managers could use in trying to address an array of competing land use issues that may individually or collectively impact wildlife populations (Boyce and McDonald 1999). RSFs are a promising new approach to understanding and modelling resource selection based on a multivariable characterization of resource use that can include any type and number of variables typical of human dominated landscapes. For example, road density, seismic lines, distance to development etc. (Boyce and McDonald 1999). Similarly, changes in habitat quality due to targeted habitat management programs for maintaining or increasing ungulate populations can be quantified. For example, the Alberta Grizzly Bear Management Plan indicated that the conservation of grizzly bear populations in Alberta depended primarily on the preservation and management of habitat and integrating ongoing ungulate habitat enhancement programs with grizzly management objectives (Nagy and Gunson 1990). Similarly, the Alberta Cougar Management Plan (Alberta Environment 1992) indicated that management, protection and habitat enhancement programs targeting cougar prey species such as elk and bighorn sheep would have important consequences for conserving cougars in Alberta. Evaluating the effects of current habitat management efforts on ungulates and their subsequent impacts on grizzly bears and cougars can be assessed through an RSF approach. RSFs can be used to develop population estimates and monitor these population trends over time given information about the quality of the landscape. RSF models are currently being developed to predict the probability of occurrence and population consequences of forestry management on grizzly bears in west central Alberta (Stenhouse and Munro 2000).

There are two general research objectives:

1) Quantify the effects of spatial heterogeneity on individual resource selection patterns and population densities; and

2) Infer the population effects from the individual resource selection models.

To develop an RSF for individual collared grizzly bear and cougar for each year, the location data of each individual will identify the "used" resource units for that animal. These will be compared to a random sample of available resource units within each animal's home (Design III, Sampling Protocol A in Manly et al. 1993) and for the entire study area (Design II, Sampling Protocol A in Manly et al. 1993) to assess individual selection patterns at these two scales (Johnson 1980). 
Variables that characterize the study area for grizzly bears and cougars will include digital data layers for habitat quality, elevation, road and trail density, distance to population centers, elevation, and slope. The values of these variables at "used" sites will be compared to the values at randomly sampled sites within the spatial extent of each home range and the study area at a resolution of $30 \mathrm{~m}$, the smallest spatial unit for Landsat data used in the analysis. A logistic regression will be fitted to these data to estimate coefficients (Manly et al. 1993). The mean coefficient for each variable, averaged across all bears and cougars, will be used to develop an RSF model that describes the relative probability of occurrence of each species in each season.

Temporally, resource selection patterns will be analyzed at different scales. Individual resource selection patterns will be modeled at the resolution of the collar data that will vary with the species and the programming for each GPS collar (1 hour for grizzly bears and 4 hours for cougars). Data will be resampled to the extent of ecological seasons: spring, summer, fall, and winter for cougars and pre-berry (den emergence to 15 July), berry (15 July-15 September), and post-berry (16 September to den entrance) for grizzly bears.

I will develop a series of candidate models (hypotheses) to address resource selection of cougars, grizzly bears, and both species together at the spatial and temporal scales defined. Akaike information criterion (AIC) will be used to select the best model from alternatives in a nested design (Burnham and Anderson 1998). Using this model, high, medium, and low probabilities of grizzly bear, cougar, and both species occurrence will be plotted within a home range and throughout the study area using a GIS. I will assume that the predictions of the RSF models are the most suitable areas for defining corridor locations for grizzly bears and cougars given their resource selection. Using GIS, the model predictions can be compared with current corridor and highway mitigation plans.

\section{Movement Models: Development and Analyses}

There are two research objectives associated with the movement research and data analyses:

1) Quantify the effects of spatial heterogeneity on individual movements and population redistribution; and,

2) Infer the rate of population spread from individual-based movement data.

Collaring each individual is an example of the individual mark-recapture approach to quantifying movement (Turchin 1998). Translating these data points constitutes a movement path. A path is the complete spatio-temporal record of the collared cougar or grizzly bear from the beginning to the end of the observation (e.g. one year). Because the collars are programmed to obtain data at such short time intervals, paths will be oversampled. I will resample the path at a variety of lower temporal or spatial resolutions (minimum spatial resolution will be $30 \mathrm{~m}$ based on Landsat data used in the analysis). Each path is represented by a series of moves defined as the displacement between two consecutive stopping points (Turchin 1998). Each move is characterized by the following measurements: move duration, length, direction, straight-line displacement (ratio of move length to duration) and the turning angle (direction of move relative to direction of the previous move). Therefore, each path can be defined by three frequency distributions: 1) move speeds; 2) move durations; and 3) and turning angles.

In order to translate individual movement data into a measure of dispersal or population redistribution, movement data for individual cougars and grizzly bears will be analyzed using the model of correlated random walk (CRW) (Turchin 1998). CRW is the simplest random walk formulation. This approach requires an analysis of moves that are then used to estimate various 
random walk parameters and predict some path-level features. CRW assumes that move durations, speeds, and turning angles are not serially correlated. This can be tested statistically. If tests indicate that CRW assumptions are not violated, I will compare the theoretical and actual net squared displacement to assess the overall appropriateness of the CRW model following methods described in Turchin (1998). If tests do not support CRW, I will develop an individuat based model incorporating movement (Turchin 1998). Null models will be developed to test whether the observed pattern of movement would be expected by chance (Gotelli and Graves 1996).

Given the initial position of an organism and its initial movement direction, and the frequency distributions associated with move speed, duration, and turning angles, it is possible to specify the probabilities of finding the organism at any point in space at any time (Turchin 1998). Movement patterns modeled as a function of the same habitat variables studied for RSFs can be used to predict where the highest probability of movements will occur, what certain habitats may be used for (foraging versus dispersal), and how movements may change given changes in the value of these habitats either through targeted enhancement efforts or industrial activity. Using GIS, these probabilities will be plotted throughout the study area.

Temporally, movement patterns will be analyzed at different scales. Individual movement patterns will be modeled at the resolution of the collar data that will vary with the species and the programming for each GPS collar (1 hour for grizzly bears and 4 hours for cougars). Data will be resampled to daily, weekly, and monthly paths to the extent of ecological seasons: spring, summer, fall, and winter for cougars and pre-berry (den emergence to 15 July), berry (15 July-15 September), and post-berry (16 September to den entrance) for grizzly bears.

\section{Linking Movement and Resource Selection Patterns}

A spatially explicit model incorporating individual movement in relation to landscape structure and resource selection patterns (above) can be used to explore how individuals and populations may respond to changing environmental conditions (Folse et al. 1989, Dunning et al. 1995, Holt et al. 1995). A spatially explicit model (SEM) such as an object-oriented simulation model or intelligent GIS model could be constructed to include resource distribution in the simulations and to test whether the correlated random walks result in movement and distribution patterns similar to movements and distribution observed in the field.

\section{Model Validation}

One approach to validating the models includes withholding a percentage of the data and running the models to see if they predict the pattern observed. In this case whether the RSF and movement models could predict the pattern observed for collared cougars and bears. In addition, I am seeking permission from the ESGBP (S. Herrero, pers. comm.) and the Sheep River cougar project (I. Ross, pers. comm.) to use their respective radiotelemetry datasets as an independent test of the RSF and movement models I develop for this research project.

\section{Anticipated Results}

A major gap in the ability to manage carnivores in fragmented landscapes is the lack of understanding about connectivity, specifically about the value and utility of corridors for facilitating movement and resource selection by carnivores. By using empirical data and spatially explicit models of resource selection and movement, I will build a map indicating what areas have the highest probability of use and occurrence for grizzly bears and cougars based on resource selection and movement patterns. Comparing these predictions at the individual, home range, and study area scale with currently designated or planned corridors will test the current ad hoc approach to corridor 
design. This approach will be tested on two species of carnivores to elucidate if species-specific responses need to be considered in corridor design and placement. This multi-scale and comprehensive approach could provide a link between individual resource selection and spatial dynamics and used to address various anticipated and planned development scenarios. There are a number of tangible benefits to local managers including:

1) The models can help define the optimal locations for placement and design of wildlife corridors in the Crowsnest Pass area given movement and habitat selection data. These corridors have application to local and regional connectivity for populations within protected areas.

2) The models can provide managers with scientifically based mitigation options for anticipated highway twinning and expansion projects in critical wildlife habitats in the Crowsnest Pass area.

3) Habitat management priorities can be co-ordinated using a scientific and robust method linking habitats for game species with game species populations. This will ultimately provide improved habitats for elk, deer (Odocoileus spp.), and bighorn sheep and enhanced hunting opportunities for Alberta hunters.

4) The models will enable managers to capitalize on the opportunity to work with private landowners and conservation organizations to identify, prioritise and secure habitats that may be important for movement and resource selection of carnivores.

5) The effectiveness of habitat management programs on game populations can be addressed directly. This will ultimately provide an important tool for monitoring game populations and permit managers to address other land uses that can direct habitat retention and protection efforts.

6) The models will enable managers to capitalize on the opportunity to work with the timber industry to maximize wildlife habitat enhancement and restoration opportunities on industry lands.

Ultimately, the results will allow managers to capitalize on opportunities to bring together conservation organizations, industry, and landowners and meld game management and preservation interests in Alberta.

Regionally, the results support and link with ongoing carnivore planning and conservation efforts such as the Wildlands Project (Soulé and Terborgh 1999) and the Yellowstone to Yukon (Y2Y) Project that focus primarily on large carnivores. These regional projects however will benefit from this project, as the models will help define and validate critical habitat linkages between protected areas in Alberta for large carnivores and their prey such as elk and bighorn sheep. 
Alberta Fish and Wildlife. 1992. Management Plan for Cougars in Alberta. Wildlife Management Planning Series No. 5. $91 \mathrm{pp}$.

Andelman, S.J., and Fagan, W.F. 2000. Umbrellas and flagships: efficient conservation surrogates or expensive mistakes? PNAS. 97(11): 5954-5959.

Apps, C. 1997. Identification of grizzly bear linkage zones along the Highway 3 corridor of southeast British Columbia and southwest Alberta. World Wildlife Fund Canada/USA and British Columbia Ministry of the Environment, Lands and Parks. 45 pp.

Apps, C. 1993. Cumulative effects assessment for large carnivores: a literature review and development strategy for the Canadian Rockies. Prep. Canadian Parks Service, Western Region, Calgary. $68 \mathrm{pp}$.

Bader, M. 2000. Spatial needs of grizzly bears in the U.S. northern Rockies. Alliance for the Wild Rockies. Special Report No. 10. Missoula, MT. 28 pp.

Beecham, J.J. 1983. Population characteristics of black bears in west central Idaho. J. Wildl. Manage. 47: 405-412.

Beers, T.W., Dress, P.E., and Wensel, L.C. 1966. Aspect transformation in site productivity research. Journal of Forestry. 64: 691-692.

Beier, P. 1996. Metapopulation models, tenacious tracing, and cougar conservation. Pages 293323. In: D.R. McCullough (ed). Metapopulations and Wildlife Conservation. Island Press, WA.

Beier, P. 1995. Dispersal of juvenile cougars in fragmented habitat. J. Wildl. Manage. 59: 228237.

Beier, P. 1993. Determining the minimum habitat areas and habitat corridors for cougars. Cons. Biol. 7: 94-108.

Beier, P., and Loe, S. 1992. A checklist for evaluating impacts to wildlife movement corridors. Wildl. Soc. Bull. 20: 434-440.

Beier, P. and Noss, R. F. 1998. Do habitat corridors provide connectivity? Cons. Biol. 12(6): 1241-1252.

Benn, B., Donelon, S., et al. 1998. Grizzly bear population and habitat status in Kananaskis Country, Alberta. A Report to the Department of Environmental Protection, Natural Resources Service, Alberta. $10 \mathrm{pp}$.

Bennett, A.F., Henien K., et al. 1994. Corridor use and the elements of corridor quality - corridors and fencerows in a farmland mosaic. Biol. Cons. 68: 155-165.

Blanchard, B.M., and Knight, R.R. 1991. Movements of Yellowstone grizzly bears. Biol. Cons. 58: 41-67.

Boone, R.B., and Hunter, M.L. 1996. Using diffusion models to simulate the effects of land use on grizzly bear dispersal in the Rocky Mountains. Land. Ecol. 11(1): 51-64.

Bow Corridor Ecosystem Advisory Group (BCEAG). 1998. Wildlife Corridor and Habitat Patch Guidelines for the Bow Valley. Revised. July 1999. 32 pp.

Boyce, M. S. and L. L. McDonald. 1999. Relating populations to habitats using resource selection functions. TREE 14: 268-272.

Brown, J.H., and Kodric-Brown, A. 1977. Turnover rates in insular biogeography: effect of immigration on extinction. Ecology. 58: 445-449.

Bunnell, F.L., and Tait, D.E.N. 1980. Bears in models and in reality - implications to management. Int. Conf. Bear Res. Manage. 3: 15-23.

Burnham, K.P., and Anderson, D.R. 1998. Model Selection and Inference: A Practical InformationTheoretic Approach. Springer-Verlag, NY.

Callaghan, C., and Jevons, S. 2001. A multi-species habitat use model for the Canmore Benchlands Wildlife Movement Corridor. Unpublished Draft Report. 38 pp. 
Carroll, C., Paquet, P. C., et al. 2000. Modeling carnivore habitat in the Rocky Mountain Region: a literature review and suggested strategy. Toronto, World Wildlife Fund Canada. 109 pp.

Clevenger, A. P. and Waltho, N. 2000. Factors influencing the effectiveness of wildlife underpasses in Banff National Park, Alberta, Canada. Cons. Biol. 14(1): 47-56.

Clevenger, A.P. 2000. Highway mitigation monitoring project - midpoint interchange. Progress Report 1, August 1999-April 2000. Canmore, AB. 13 pp. + appendices.

Craighead, F.L, and Vyse, E.R. 1996. Brown/grizzly bear metapopulations. Pages 325-351. In: McCullough, D.R. (ed). Metapopulations and Wildlife Conservation. Island Press, WA.

Crone, E.E., Doak, D., and Pokki, J. 2001. Ecological influences on the dynamics of a field vole metapopulation. Ecology. 82(3): 831-843.

Doak, D.F. 1995. Source-sink models and the problem of habitat degradation: general models and applications to the Yellowstone grizzly. Cons. Biol. 9: 1370-1379.

Duke, D. 2000. Wildlife corridors around developed areas in Banff National Park. Progress Report 1999/2000. 46 pp.

Dunning, J.B., Jr., Stewart, D.L., Danielson, B., et al. 1995. Spatially explicit population models: current forms and future uses. Ecol. Appl. 5: 3-11.

Dunning, J.B., Danielson, B.J., and Pulliam, H.R. 1992. Ecological processes that affect populations in complex landscapes. Oikos. 65: 169-175.

Fahrig, L, and Merriam. G. 1994. Conservation of fragmented populations. Cons. Biol. 8: 50-59.

Folse, L.J., Packard, J.M, and Grant, W.E. 1989. AI modeling of animal movements in a heterogeneous habitat. Ecol. Model. 46: 57-72.

Gibeau, M.L. 2000. A conservation biology approach to management of grizzly bears in Banff National Park, Alberta. Unpublished Ph.D. Thesis, University of Calgary, AB. 129 pp.

Gibeau, M.L., and Heuer, K. 1996. Effects of transportation on large carnivores in the Bow River Valley, Alberta. In: Evink, G.L., Garrett, P., Zeigler, D., Berry, J. (eds). Trends in Addressing Transportation Related Wildlife Mortality Seminar. State of Florida Department of Transportation, Tallahassee, FL.

Gilliam, J.F., and Fraser, D.F. 2001. Movement in corridors: enhancement by predation threat, disturbance, and habitat structure. Ecology. 82(1): 258-273.

Gotelli, N.J., and Graves, G.R. 1996. Null models in ecology. Smithsonian Institution. Washington, D.C.

Green, J., Pacas, C., et al. (eds). 1996. Ecological Outlooks Project. A cumulative effects assessment and futures outlook of the Banff Bow Valley. Prepared for the Banff Bow Valley Study. Department of Canadian Heritage, Ottawa, ON.

Gunson, J.R. 1995. Analysis of grizzly bear mortalities in 1972-1994. Alberta Environmental Protection, Natural Resources Service. Occasional Paper No. 16. 101 pp.

Haas, C.A. 1994. Dispersal and use of corridors by birds in wooded patches on an agricultural landscape. Cons. Biol. 9: 845-854.

Haddad, N.M., Rosenberg, D.K., et al. 2000. On experimentation and the study of corridors: response to Beier and Noss. Cons. Biol. 14(5): 1543-1545.

Hanski, I. 1998. Metapopulation dynamics. Nature. 396: 41-49.

Hanski, I, and Gilpin M.E. (eds). 1991. Metapopulation dynamics and landscape ecology. Academic Press.

Harris, L.D., Hoctor, T., Maehr, D., and Sanderson, J. 1996. The role of networks and corridors in enhancing the value and protection of parks and equivalent areas. Pages 173-197. In: Wright, R.G. (ed). National Parks and Protected Areas: Their Role in Environmental Protection. Blackwell Science, MA.

Harrison, S. 1991. Local extinction in a metapopulation context: an empirical evaluation. Biol. J. Linn. Soc. 42: 73-88. 
Hastings, A., and Harrison, S. 1994. Metapopulation dynamics and genetics. Ann. Rev. Ecol. Syst. 25: $167-188$.

Herrero, S., and Herrero, J. 1996. Cheviot mine proposal: specific and cumulative environmental effects analysis for mammalian carnivores. $122 \mathrm{pp}$.

Herrero, S., McCrory, W., and Pelchat, B. 1986. The application of grizzly bear habitat evaluation to trail and campsite locations in Kananaskis Provincial Park, Alberta. Int. Conf. Bear Res. Manage. 6: 187-193.

Heuer, K. 1995. Wildlife corridors around developed areas of Banff National Park. Prepared for Parks Canada Banff Warden Service. Banff, AB. 78 pp.

Heuer, K., Owchar, R., Duke, D., and Antonation, S. 1998. Wildlife corridors around developed areas in Banff National Park. Winter 1996/97. Prepared for Parks Canada Banff Warden Service. Banff, AB. 46 pp.

Hobbs, R.J. 1992. The role of corridors in conservation: solution or bandwagon? TREE. 7: 389392.

Holt, R.D. , Pacala, S.W., Smith, T.W., and Liu, J. 1995. Linking contemporary vegetation models with spatially explicit animal population models. Ecol. Appl. 5: 20-27.

Hudson, W.E. 1991. Landscape linkages and biodiversity. Island Press, Washington, D.C. Inglis, G., and Underwood, A.J. 1992. Comments on some designs proposed for experiments on the biological importance of corridors. Cons. Biol. 6: 581-586.

Jalktozy, M., and Ross, I. 1991. Cougars in Waterton Lakes, Banff, and Jasper National Parks. Prepared for Parks Canada. Arc Associated Resource Consultants Ltd., Calgary. 17 pp.

Jalkotzy, M.G., P.I. Ross, and J. Wierzchowski. 1999. Cougar habitat use in southwestern Alberta. Prepared for ACA. Arc Wildlife Services Ltd., Calgary. 32 pp. + app.

Jalkotzy, M.G., Ross, P.I., and Nasserden, M.D. 1997. The effects of linear developments on wildlife: a review of selected scientific literature. Prep. For Canadian Association of Petroleum Producers. Arc Wildlife Services Ltd., Calgary. 115 pp.

Johnson, D. H. 1980. The comparison of usage and availability measurements for evaluating resource preference. Ecology. 6(1): 65-71.

Kareiva, P. 1990. Population dynamics in spatially complex environments: theory and data. Philosophical Transactions of the Royal Society of London, B Series. 53-68.

Kelleyhouse, D.G. 1977. Habitat utilization by black bears in northern California. Int. Conf. Bear Res. Manage. 4: 221-227.

Kozakiewicz, M. and Szacki, J. 1995. Movements of small mammals in a landscape: patch restriction or nomadism? Pages 78-94. In: Lidicker, Jr., W.Z. (ed.). Landscape Approaches in Mammalian Ecology and Conservation. University of Minnesota Press, Minnesota, MN.

Lambeck, R.J. 1997. Focal species: a multi-species umbrella for nature conservation. Cons. Biol. 11: 849-856.

Lidicker, Jr., W.Z., and Koenig, W.D. 1996. Responses of terrestrial vertebrates to habitat edges and corridors. Pages 85-109. In: McCullough, D.R. (ed). Metapopulations and Wildlife Conservation. Island Press, WA.

Little, C.E. 1990. Greenways for America. John Hopkins University Press, Baltimore, MD.

Liu, J., Dunning, Jr., J.B., and Pulliam, H.R. 1995. Potential effects of a forest management plan on Bachmann's Sparrows (Aimophila aestivalis): linking a Spatially Explicit Model with GIS. Cons. Biol. 9(1): 62-75.

MacArthur, R.H. and E.O. Wilson. 1967. The Theory of Island Biogeography. Princeton University Press, Princeton.

Mace, R.D., Waller, J.S. et al. 1999. Landscape evaluation of grizzly bear habitat in Western Montana. Cons. Biol. 13 (2): 367-377. 
Maehr, D.S., and Cox, J.A. 1995. Landscape features and panthers in Florida. Cons. Biol. 9(5): 1008-1019.

Maehr, D.S. 1990. The Florida panther and private lands. Cons. Biol. 4: 167-170.

Manly, B., McDonald, L., and Thomas, D. 1993. Resource selection by animals. Chapman and Hall.

Manville, A.M. 1983. Human impact on the black bear in Michigan's lower peninsula. Int. Conf. Bear Res. Manage. 5: 20-33

Mattson, D.J., Herrero, S., Wright, R.G., and Pease, C.M. 1996. Designing and managing protected areas for grizzly bears: how much is enough? Pages 133-164. In: R.G. Wright (ed). National Parks and Protected Areas: Their Role in Environmental Protection. Blackwell Science, MA.

McCrory, W. and Herrero, S. 1982. A review of the historical status of the grizzly bear in Kananaskis Country, Alberta. Prep. For Alberta Fish and Wildl. Div., Calgary. Bios Environ. Res. And Planning Assoc. Ltd., Calgary. 249 pp.

McLellan, B.N. 1990. Relationships between human industrial activity and grizzly bears. Int. Conf. Bear Res. Manage. 8: 57-64.

Merriam, G. 1991. Corridors and connectivity: animal populations in heterogeneous environments. Pages 133-142. In: Saunders, D.A., and Hobbs, R.J. (eds.). Nature Conservation 2: The Role of Corridors. Surrey Beatty \& Sons, Chipping Norton, New South Wales, Australia.

Merriam, G. 1995. Movement in spatially divided populations: responses to landscape structure. Pages 64-77. In: Lidicker, Jr., W.Z. (ed.). Landscape Approaches in Mammalian Ecology and Conservation. University of Minnesota Press, Minnesota, MN.

Merrill, T., D. J. Mattson, et al. 1999. Defining landscapes suitable for restoration of grizzly bears Ursus arctos in Idaho. Bib Cons. 87: 231 -248.

Mowat, G., and Strobeck, C. 2000. Estimating population size of grizzly bears using hair capture, DNA profiling, and mark-recapture analysis. J. Wildl. Manage. 64(1): 183-193.

Nagy, J.A., and Gunson, J.R.. 1990. Management plan for grizzly bears in Alberta. Wildlife Management Planning Series No. 2. Alberta Forestry Lands and Wildlife. 164 pp.

Nicholls, A.O., and Margules, C.R. 1991. The design of studies to demonstrate the biological importance of corridors. Pages 49-61. In: Saunders, D.A., and Hobbs, R.J. (eds.). Nature Conservation 2: The Role of Corridors. Surrey Beatty \& Sons, 1991. Chipping Norton, New South Wales, Australia.

Noss, R.F. 1992. The Wildlands Project Land Conservation Strategy. Wild Earth (special edition): 10-25.

Noss, R. F. 1987. Corridors in real landscapes: a reply to Simberloff and Cox. Cons. Biol. 1: 159164.

Noss, R.F. 1983. A regional landscape approach to maintain diversity. BioScience. 33: 700-706.

Noss, R. F., H. B. Quigley, et al. 1996. Conservation biology and carnivore conservation in the Rocky Mountains. Cons. Biol. 10(4): 949-963.

Paquet, P. C., M. L. Gibeau, et al. 1994. Wildlife Corridors in the Bow River Valley, Alberta: a strategy for maintaining well-distributed, viable populations of wildlife. Canmore, Bow River Valley Corridor Task Force: 37 pp.

Picton, H.D. 1986. A possible link between Yellowstone and Glacier grizzly bear populations. Int. Conf. Bear Res. Manage. 6: 7-10.

Purves, H.D., White, C.A., and Paquet, P.C. 1992. Wolf and grizzly bear habitat use and displacement by human use in Banff, Yoho, and Kootenay National Parks: a preliminary analysis. Canadian Parks Service, Banff. 45 pp.

Rosenberg, D.K., Noon, B.R., and Meslow, E.C. 1997. Biological corridors: form, function, and efficacy. BioScience. 47: 677-687. 
Ross, P.I. and Jalkotzy, M.G. 1992. Characteristics of a hunted population of cougars in southwestern Alberta. J. Wildl. Manage. 56: 417-426.

Ruckelshaus, C., Hartway, C., and Kareiva, P. 1997. Assessing the data requirements of spatially explicit dispersal models. Cons. Biol. 11(6): 1298-1306.

Rushton, S.P., Lurz, P.W.W., Fuller, R., and Garson, P.J. 1997. Modelling the distribution of the red and grey squirrel at the landscape scale: a combined GIS and population dynamics approach. J. Appl. Ecol. 34: 1137-1154.

Ruth, T.K., Logan, K.A., Sweanor, L.L., Hornocker, M.G., and Temple, L.J. 1998. Evaluating cougar translocation in New Mexico. J. Wildl. Manage. 62(4): 1264-1275.

Saunders, D.A., and Hobbs, R.J. (Eds.). 1991. Nature Conservation 2: The Role of Corridors. Surrey Beatty \& Sons, Chipping Norton, New South Wales, Australia. 442 pp.

Schmiegelow, F.K.A., Machtans, C.S., and Hannon, S.J. 1997. Are boreal birds resilient to forest fragmentation? An experimental study of short-term community responses. Ecology. 78: 19141932.

Servheen, C. 1990. The status and conservation of the bears of the world. Int. Conf. Bear Res. Manage. Monogr. 2.

Simberloff, D. and J. Cox. 1987. Consequences and costs of conservation corridors. Cons. Biol. 1: 63-71.

Simberloff, D., J. A. Farr, et al. 1992. Movement corridors: conservation bargains or poor investments? Cons. Biol. 6: 493-504.

Smith, D.S., and Hellmund, P.C. 1993. Ecology of greenways - design and function of linear conservation areas. University of Minnesota Press, Minneapolis.

Soulé, M. E. and Terborgh, J. 1999. Continental Conservation: Scientific Foundations of Regional Reserve Networks. Island Press, Washington D.C.

Soulé, M.E. 1991. Countering habitat fragmentation: theory and strategy. Pages 91-104. In: Hudson, W.E. (ed). Landscape Linkages and Biodiversity. Defenders of Wildlife, Island Press, WA.

Stenhouse, G., and Munro, R. 2000. Foothills Model Forest Grizzly Bear Research Report 1999 Annual Report. 107 pp.

Stern, S.J. 1998. Field studies of large mobile organisms: scale, movement, and habitat utilization. Pages 289-307. In: Peterson, D.L. and Parker, V.T. (eds). Ecological Scale: Theory and Applications. Columbia University Press, New York.

Stevens, S., Callaghan, C., and Owchar, R. 1996. A survey of wildlife corridors in the Bow Valley of Banff National Park, Winter 1994/95. $41 \mathrm{pp}$.

Stringham, S.F. 1990. Grizzly bear reproductive rate relative to body size. Int. Conf. Bear Res. Manage. 8: 433-443.

Sweanor, L.L., Logan, K.A., et al. 2000. Cougar dispersal patterns, metapopulation dynamics and conservation. Cons. Biol. 14(3): 798-808.

Terborgh, J., Estes, J. A. et al. 1999. The role of top carnivores in regulating terrestrial ecosystems. Pages 39-64. In: Soulé, M. E. and Terborgh, J. (eds.). Continental Conservation: scientific foundations of regional reserve networks. Island Press, Washington.

Tischendorf, L., and Fahrig, L. 2000. On the usage and measurement of landscape connectivity. Oikos. 90: 7-19.

Turchin, P. 1998. Quantitative Analysis of Movement. Measuring and Modeling Population Redistribution in Animals and Plants. Sinauer Associates, Massachusetts.

Turner, M.G., Y. Wu, W.H. Romme, and L.L. Wallace. 1993. A landscape simulation model of winter foraging by large ungulates. Ecol. Model. 69: 163-184.

Turner, M.G., and Gardner, R.H. (eds). 1991. Quantitative methods in landscape ecology. The analysis and interpretation of landscape heterogeneity. Springer-Verlag, New York. 517 pp. 
Turner, M.G. 1989. Landscape ecology: the effect of pattern on process. Ann. Rev. Ecol. Syst. 20: 171-197.

Weaver, J. L., P. C. Paquet, et al. 1996. Resilience and conservation of large carnivores in the Rocky Mountains. Cons. Biol. 10(4): 964-976.

Wei, J., and Jeske, C. 2000. Spatial modeling of the geographic distribution of wildlife populations: a case study in the lower Mississippi River region. Ecol. Model. 132: 95-104.

Wiens, J.A. 1991. Metapopulation dynamics and landscape ecology. Pages 43-62. In: Hanski, I, and Gilpin M.E. (eds). Metapopulation dynamics and landscape ecology. Academic Press.

Wiens, J.A., and Milne, B.T. 1989. Scaling of 'landscapes' in landscape ecology, or, landscape ecology from a beetle's perspective. Landscape Ecology. 3: 87-96.

Wilcox, B.A. and Murphy, D.D. 1985. Conservation strategy: the effects of fragmentation on extinction. Am. Nat. 125: 879-887.

Woodroffe, R. and J. R. Ginsberg 1998. Edge effects and the extinction of populations inside protected areas. Science 280: 2126-2128. 

National Library of Canada
Bibliothèque nationale du Canada

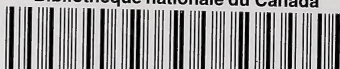

3 3286523363998 